\author{
Military Technical College \\ Kobry El-Kobbah, \\ Cairo, Egypt.
}

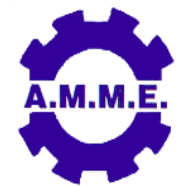
$18^{\text {th }}$ International Conference
on Applied Mechanics and
Mechanical Engineering.

\title{
IDENTIFICATION OF CRITICAL SUCCESS FACTORS FOR TOTAL PRODUCTIVE MAINTENANCE
}

\author{
S. N. Seleem ${ }^{1}$, El-Awady Attia ${ }^{2}$ and A. El-Assal ${ }^{3}$
}

\begin{abstract}
To remain competitive in the current working environment, firms focus on adopting performance improvement approaches that support in satisfying their customer needs and reducing their production expenses. Total Productive Maintenance (TPM) is considered as one of the most important programs that enhance the overall internal process; hence, significant operational results can be easily achieved. On the other side, it is crucial to sustain such results over time. To gain such sustainability, companies need to identify the critical success factors for the implementation of TPM programs. Moreover, they need to introduce and implement actions that support these critical success factors as a foundation before establishing a TPM program. In this paper, Decision Making Trial and Evaluation Laboratory (DEMATEL) method used to identify such critical success factors. The proposed approach applied in an Egyptian factory that is dedicated to produce a set of plastic parts. After applying the proposed approach, it concluded that "Cross-functional team work", "Setting organization objectives", "Providing on-job training" and "Availability of information" are the most critical factors. After working on such factors and starting the TPM program, key performance indicators such as the overall equipment effectiveness (OEE) improved from $60.0 \%$ to $73.1 \%$ in a period of 15 months.
\end{abstract}

\section{KEYWORDS}

Total Productive Maintenance, Success Factors, DEMATEL, Overall Equipment Efficiency.

${ }^{1}$ Refrigerators Plant Manager, Elaraby Group for industrial engineering $3^{\text {rd }}$ Industrial zone, Quesna, Egypt. Email: samehnaeem100@gmail.com.

${ }^{2}$ Assistant Professor, Mechanical engineering department, Shoubra faculty of engineering, Benha University, Egypt. Email: elawady.attia@feng.bu.edu.eg.

${ }^{3}$ Professor of mechanical engineering, Mechanical engineering department, Benha faculty of engineering, Benha University, Benha, Egypt. Email: ahmed.el-assal@bhit.bu.edu.eg. 


\section{INTRODUCTION}

In the demand-driven environment, many challenges confront modern industrial firms. These challenges emphasize firms upon the re-examination of their systems in order to implement effective management approaches that reduce wastes, improve their competitiveness and improve their probability of success. Firms' facilities or equipment considered as one of the most important resources. Increasing the capability of such facilities improves the firm's capability to satisfy customer expectations. The best practice of maintenance programs improves the capability of such equipment and ensures the firm's success in such working environment. In other words, organizations should adopt integrated strategies to achieve efficient maintenance with appropriate manufacturing level. Strategies that integrate maintenance with manufacturing functions needed to optimize reliability, availability, and maintainability and production system performance [1]. Total Productive Maintenance (TPM) is recognized as one of the significant operational strategies that focus on building product quality by maximizing equipment effectiveness and optimizing equipment reliability. Furthermore, its philosophy depends on the concept of both continuous improvement and cross-functional teamwork that focuses on maintaining equipment's basic condition in order to extend its useful life span [2]. The whole organization staff should work together during the application of TPM program, i.e. shop floor operators, maintenance personnel, management and the whole organization are involved and working together to achieve the goals of TPM. The starting point of TPM is to actualize collaboration between manufacturing and maintenance functions by a combination of continuous improvement, and good working practices [3]. The main objectives of the implementation of TPM are to ensure efficient management of plant assets through eliminating of the six big production losses, which are breakdowns, setup and adjustment time, idling and minor stoppages, reduced speed, process defects and yield losses [4]. In addition, the implementation of TPM in an organization can lead to the realization of intangible benefits in the form of the improved image of the organization, which leads to the probability of increasing the production orders.

After the introduction of TPM activities, production operators take care of machines by themselves without ordered to do that. Moreover, with the achievement of TPM objectives, operators earn more confidence in their capability and the organizations understand the importance of the employees' contribution towards the achievement of efficient manufacturing performance [5]. The philosophy of TPM converts the style of the traditional maintenance system from being reactive to being more proactive by maintaining the equipment in the appropriate condition at all times. The objective is to continuously improve the availability of production system and minimize depreciation of equipment to maximize its effectiveness. These objectives require active and real management commitment as well as the involvement of cross-functional teams and small group activities to achieve incremental and radical improvements. Furthermore, TPM aims to prevent losses due to equipment suddenly breakdowns, production rate losses or defects occurring during planned production time and during setup times, i.e. increasing the Overall Equipment Effectiveness (OEE). Nakajima [6] suggested that equipment should operate at $100 \%$ capacity for $100 \%$ of the time, for such reasons, TPM has three main objectives: zero defects, zero accident, and zero breakdowns. The benefits arising from TPM can be classified into six categories including productivity $(P)$, quality $(Q)$, cost $(C)$, delivery $(D)$, safety $(S)$ and morale (M). Benchmarking of these measures (OEE, P, Q, C, D, S and M) shall qualify the 
organization to realize TPM main objectives. TPM initiatives as proposed by Japan Institute of Plant Maintenance (JIPM) involve an eight-pillar implementation plan that results in radical improvements in system productivity through controlled maintenance, reduction in maintenance costs, and reduced setup and breakdowns [7]. Moreover, TPM provides the way for excellent planning, organizing, monitoring, and controlling practices through its eight pillars that involving: autonomous maintenance; focused improvement; planned maintenance; quality maintenance; education and training; safety, health and environment; office TPM; and development management [8]. Besides, TPM approach aims to increase production capacity without additional investments in new equipment or human resources. It provides an effective way of deploying maintenance tasks by involving all employees on a continuous basis. commonly total employee involvement, autonomous maintenance that implemented by manufacturing operators, continuous improvement activities, and teams' activities that improve the overall equipment effectiveness (OEE), are the principles embraced by TPM. OEE employed as the core quantitative metric for measuring the effectiveness of a production system. It is the central theme of a TPM improvement strategy. It provides a systematic manner for establishing production targets and incorporates practical management tools in order to achieve a complete view of equipment availability rate, production rate, and quality rate. OEE computed by multiplying equipment availability, performance efficiency of process and the rate of products quality [9].The bottom-line achievement of a successful TPM implementation in an organization cover lower operational costs, extend equipment life span and lower overall maintenance expenses [4].

Regarding the applicability of TPM, it is successfully implemented in many industrial plants such as Indian industrials firms [10], and Malaysian firms [11]. In addition, Bamber and Sharp [12] concluded that some UK small and medium size enterprises apply TPM program. Besides, Lin et al. [13] pointed out that TPM is applicable for large size organizations such as construction machinery industrial firms. Moreover, TPM applications extended to food, pharmaceutical, and drug manufacturing [14].

In reasons of the importance of TPM as an effective performance improvement tool, the current paper proposes to investigate the most critical success factors of TPM. After knowing these factors, industrial firms can work to support and strengthen these factors to sustain the application of TPM program. This shall accelerate the expected results such as increasing OEE. Moreover, the identification of these success factors can guide decision makers to the accurate managerial and technical actions that can lead to the achievement of the desired outcomes. Moreover, these success factors shall sustain the earned results on the long term. In the previous literatures, many authors discussed the success factors of TPM. The current work is not only review these factors but also prioritize them by considering industrial firm situation and by utilizing the experts' knowledge and their experience.

\section{LITERATURE REVIEW}

The literature provides many success factors for the TPM approach. Generally, for any industrial plant, the goals and objectives of the TPM program should be aligned with the organizations' overall strategic objectives. This trend enhances the potential of TPM and assures its successful implementation. Lycke and Akersten [15] concluded that resources planning and teams preparation are essential before the 
implementation of TPM, therefore top management's involvement, commitment and understanding of TPM approach is considered as a critical success factor. Nakajima [6] stated that top management involvement and support needed to create and establish a favorable environment for TPM implementation. Parida and Kumar [16] found that, in order to develop a success TPM program, all levels of employees must be involved and committed to the TPM measurement activities. Rodrigues and Hatakeyama [17] concluded that the success of TPM implementation closely related to the management of employees. In additions, Hansson et al. [18] identified another two factors: the first is the enhancement of culture change before applying TPM, and the second is the adoption of the continuous improvement process as a daily common works. These two factors can be considered as success factors that support applying TPM approach [19]. Moreover, Groote [20] suggested an approach to evaluate maintenance effectiveness based on quality review and quantifiable maintenance performance indicators. He proposed that the effectiveness of maintenance functions defined through relative economic and technical measures, to allow the management to monitor the progress of its performance and to make optimal decisions for improving maintenance management. Consequently, he concluded that monitoring of maintenance KPIs (e.g. OEE or cost reduction of the maintenance work) considered as success factors that enhance the implementations of TPM. In addition, Bohoris et al. [21] illustrated that TPM projects are piloted on specific machines by focusing on reliability improvement, the remaining can be done relying on changing management style or/and integrating both production and maintenance activities. The target of TPM can be achieved by developing crossfunctional teams who act as catalysts for successful implementation within the industrial firm [22]. Moreover, providing appropriate training modules to cover the lack of skills and knowledge [23], [24] and to increase employee involvement is another TPM success factor [25]. Likewise, conducting benchmarking activities that provide major measures for activate maintenance efficiency to achieve excellent competitiveness is concluded as one of TPM success factors by [26]. McKone et al. [27] identified six major success factors for the implementation of TPM that includes training, early equipment design, early product design, focused improvement teams, support group activities, and autonomous and planned maintenance. The implementation of TPM program can be supported with many actions, Maier et al. [10] discussed these supporters that include: preventive maintenance, team-working, shop floor employee competencies, measurement and information availability, work environment, work documentation, extent of operator involvement in maintenance activities, and establishment of a rewarding system. From the previous literatures, also referring to the work of Alorom [28], and Mohamed and Mohanad [29] a set of 20 success factors (SF) for TPM summarized as follow:

SF1. Top management involvement and commitment: [6], [17], [18] and [21]

SF2. Applying 5S program: [6]

SF3. Resources planning: [15]

SF4. Alignment of TPM objectives with the organization objectives: [10]

SF5. Cross-functional teamwork: [15], [16], [17], [19], [20], [22], [27] and [10]

SF6. Setting organization objectives: [15]

SF7. Culture change: [18] and [21]

SF8. Utilization of the continuous improvement approach: [18] and [19]

SF9. Monitoring and controlling of maintenance KPIs: [20]

SF10. Applying reliability improvement pilot projects: [21]

SF11. Providing on-job training: [22], [23], [24] and [27]

SF12. Employee involvement: [25] and [10] 
SF13. Conducting benchmarking activities: [26]

SF14. Early equipment design considerations: [27]

SF15. Supporting small group activity toward implementing autonomous maintenance: [27]

SF16. Early product design considerations: [27]

SF17. Executing planned/preventive maintenance: [27] and [10]

SF18. Maintenance work documenting: [10]

SF19. Information availability: [10]

SF20. Establishment of a rewarding system: [10]

The question is which of these factors are the most significant, for the success of the implementation process of TPM. To answer this question, the DEMATEL method proposed for analyzing the interrelationships that may be exist between factors.

The remainder of this paper organized as follows: in section 3, all calculations and steps of DEMATEL method will clearly introduced. While section 4 represents the case study, it illustrates determining and prioritizing of the TPM success factors by using DEMATEL method. Finally, section 5 represents the conclusions of this work.

\section{DEMATEL PROCESS}

In the current paper, the Decision Making Trial and Evaluation Laboratory (DEMATEL) method adopted to identify the significant success factors of the TPM. This investigation process can support the implementation of TPM. The DEMATEL method was developed in 1970's at Battelle Memorial Institute at Geneva Research Center by A. Duval, E. Fontela and A. Gabus. It has developed to solve complex problem in different applications by expert's attitudes [29]. Recently, DEMATEL becomes a popular method, in reasons of its capability to evaluate the inter-wined causes and effect relationships in a structural model. This methodology is able to verify interdependence among the attributes or features and try to reflect the interrelationship between variables [30]. Here, DEMATEL method is adopted to prioritize TPM success factors and to classify them into two main groups: causes and effects groups. This leads to identify the most important factors (causes group). In order to have rapid results, it is important to start the action plan of the TPM with supporting the factors that have the higher contributions or higher importance parameter (causes group). Relying on the work of [31] the procedures of DEMATEL method can summarized as follow:

The preparation step: the preparation step is to collect the different factors to be investigated. In the current case based analysis, the factors are that required for success implementation of the TPM program. Those factors are collected based on the previous literature work. In order to represent the interrelationships between those factors, an assessment scale should be defined. This scale is used to express the degree of influence or the impact of a given factor to another. A typical range for this scale is zero to three, where zero represents no influence and three represents very high influence. After that, these factors can be represented in an empty square matrix, in which the matrix columns and rows represent the factors.

Calculation of the "Direct Relation Matrix": the step is started by asking a set of experts to indicate the level to which they believe that any of the factors influences 
each other. One can get from every expert an $(\mathrm{N} \times \mathrm{N})$ answer matrix, where $\mathrm{N}$ is the number of factors. To integrate all opinions of all experts, an average matrix can be computed. This average matrix is known as the "direct relation matrix". In this matrix, each value $\left(a_{i j}\right)$ indicates the degree in which factor $i$ affects the factor $j$.

Normalize the direct relation matrix $\mathbf{D}$ : this step is performed by dividing each element in the direct relation matrix by the largest row sum of the same matrix.

Calculating the "Total Relation Matrix (T)": according to [32], it can compute as:

$$
\mathrm{T}=\mathrm{D} \times(\mathrm{I}-\mathrm{D})^{-1}
$$

where, $(\mathrm{I})$ is the identity matrix.

Suppose that the $R_{i}$ is the sum of $i^{\text {th }}$ row in the total relation matrix $T$, then $R_{i}$ indicates the effects given by factor $i$ to the other factors. Similarly, suppose that $C_{j}$ is the sum of $j^{\text {th }}$ columns in $T$, and then $C_{j}$ represents the effects received by the factor $j$ by the other factors. Relying on the effect given $R_{i}$ and the effect received $C_{j}$, the degree of importance and the net effect can be computed. Degree of importance $=R_{i}$ $+C_{j}$. and Net effect $=R_{i}-C_{j}$ for each $\mathrm{i}=\mathrm{j}$ and $\mathrm{i}=1,2, \ldots \mathrm{N}$ and $\mathrm{j}=1,2, \ldots \mathrm{N}$.

The following section represents a full representation of DEMATEL method to investigate the critical success factors for TPM. This case based analysis adopted by an Egyptian factory that dedicated to produce plastic parts from mid-2016 to achieve the firm's goals. The methodology involves operational managers to prioritize and strengthen the TPM success factors that shall lead to achieve the organization objectives.

\section{THE INVESTIGATION STUDY}

Each organization has its exclusive constraints, problems and experts. Manufacturing experts are often involved on mapping firm's directions. Consequently, the success factors of TPM identified, analyzed, prioritized and reinforced based on the opinion and beliefs of the firm's experts. The firm under considerations decided to start implementing this work with a manufacturing system that produces the plastic inner cabinet of the fridge. The firm aims to find a focused TPM success factors that support achieving its strategic goal in relatively short time and with optimal usage of resources before and during the implementation of a TPM program. The top management selects ten experts in 2016 together with the authors. The manufacturing experts have different experience in all production areas in the specified factory with extensive experience. The success factors of TPM are selected based on the previous literatures review and as listed before in this work. As stated before a set of twenty success factors are found in the literature. The question is "which of these factors have the significant effect on the implementation of TPM". In order to answer this question, the DEMATEL method is proposed as a group decision-making technique. This method can prioritize these factors based on the degree of their importance. 


\section{Applying DEMATEL Method}

For managing and ranking the success factors of TPM, the DEMATEL method is adopted and performed. First, a set of ten experts were asked to assess the impact of each factor on each other factors using a scale of zero to four (i.e. zero $=$ no influence, one = low influence, two = moderate influence, three $=$ high influence and four $=$ very high influence). Each expert was given an empty matrix, this squared matrix is $(20 \times 20$ matrix) in which rows and columns contain the 20 success factors. Each one of experts asked to fill his template by using the previous scale. Then these matrices aggregated to construct the direct/average relation matrix shown in Table 1 by calculating the average impact of the ten experts. It shows the initial direct effects based on the expert's opinions that a success factor exerts on and receives from other factors. After that, the Normalized matrix and the Total relation matrix developed as listed respectively in Table 2 and Table 3.

Based on the total relation matrix, the effects that success factors exert $\left(R_{i}\right)$ and receive $\left(C_{j}\right)$ are calculated. Relying on $R_{i}$ and $C_{j}$ the degree of importance and the net effect can be computed. Fig. 1 presents the a scatter diagram, it represents $\left(R_{i}\right.$ $\left.C_{j}\right)$ with respect to $\left(R_{i}+C_{j}\right)$, this figure is known as the causal and effect diagram of the success factors. Table 4 represents the values of $R_{i}, C_{j},\left(R_{i}-C_{j}\right)$, and $\left(R_{i}+C_{j}\right)$ for all TPM success factors.

Subsequently, the authors together with the experts classified these success factors by observing $\left(\mathrm{R}_{\mathrm{i}}-\mathrm{C}_{\mathrm{j}}\right)$ value into two main groups:

- Factors have positive net effect \{SF9, SF1, SF11, SF6, SF19, SF13, SF4, SF5, SF10, SF3, SF20, and SF18\}. This group is known as cause factors.

- Factors have negative net effect \{SF7, SF15, SF8, SF16, SF17, SF12, SF2, and SF14\}. This set of factors known as the effect factors.

Based on this classification, factors of the first group (cause factors) are considered as the most important factors. While factors of the second group (effect factors) represents the factors that are affected by those factors of the first group. Moreover, regarding to the given impact $R_{i}$ Fig. 2 illustrates the success factors in descending order, it is observed that SF5: "cross functional team work" has the highest given value, while SF16: "early product design considerations" has the lowest given value i.e., it is not important during TPM applications.

\section{Analysis for Critical Success Factors}

The critical success factors of TPM identified and prioritized by observing both Fig. 1 and Fig. 2. Among all factors in the cause group (group 1), the following have the highest given impact $R_{i}$ : "SF5: Cross-functional team work", "SF6: Setting organization objectives", "SF11: Providing on-job training" and "SF19: Availability of information". So, these four factors considered as the most critical success factors of the implementation of the TPM. As shown by Fig.2 these factors form a cluster of great net-effect and degree of importance (Group 1). These cause factors have higher given impact, so more attention should be exerted to strengthen them in order to enhance the effect factors (Group 2) as a result i.e. improving these four factors can easily enhance others. The subsequent important factors are \{SF4, SF9, SF1, SF10, SF18, SF3, and SF20\}; these cause factors (located in: group one) respectively ranked relying on $R_{i}$ values. Moreover, SF16: early product design 
consideration not considered as a success factors. This shall lead to the fact of TPM applicability regardless type of manufactured products. For easily adopt the TPM, the firm should strength the prioritized success factors, and put an action plan to improve them before starting the TPM program. This shall accelerate the TPM steps and achieve sustainable results.

\section{Putting Success Factors into Actions}

After providing this work, the recommended actions needed to strengthen the identified critical success factors could classified into two perspectives:

- Training Perspectives, in which the company provided a set of training program that includes -Team building, -Improving Leadership skills, -development of the business plan, TPM awareness, maintenance methods and strategies, hydraulics and pneumatics circuits, and basic machine elements. These training programs provided to the maintenance and production labors and supervisors.

- Managing Perspectives, in which the company established new rules such as: Forming cross functional teams, -Setting relevant operational and maintenance objectives aligned with the firm's strategic objectives, and putting indicators in all working areas using dashboards, -Establishing monthly rewarding system, Performing monthly periodic meeting between top management and supervisors.

As described, the organization applied series of training programs to enhance the leadership skills and attitude focusing on supervisors and head of departments. In addition, training programs related to culture change, and leadership skills. Moreover top management are holding two meeting monthly with supervisors and head of departments to follow up improvement actions and progress and follow up the relevant operational and maintenance indicators, and to provide the needed support as a type of commitment. Another type of the top management commitment is the establishment of a reward system. The best three TPM pilot projects selected yearly based on clear criteria to motivate labors and to improve the predefined indicators continually. These indicators also illustrated in each workstation or department using the dashboards. All operators together with maintenance labors make daily stand up meeting to be involved with the current work challenges, and to follow up the autonomous maintenance tasks.

These different considerations enhanced the implementation of the TPM program. It reported in April/ 2017 that the average OEE significantly improved from $60 \%$ to $73.1 \%$, as illustrated in Fig. 3, because of strengthen the identified success factors. In addition, Table 5 represent the value of OEE monthly, as described before OEE = Availability rate $x$ Performance rate $x$ Quality rate. This improvement leads to save cost due to eliminating of overtime working hours, and eliminating the needs of buying an additional machine. These significant results indicate the criticality of identifying the critical success factors of any performance improvement tactic before starting its application.

\section{CONCLUSIONS}

The current paper proposed a research methodology with a case based analysis to select and prioritize the critical success factors for TPM, which support in achieving 
organization's operational and maintenance objectives. The proposed work developed based on managing experts' knowledge by utilizing DEMATEL method. The proposed work adopted in an Egyptian manufacturing firm from 2016, in one of its factories that is dedicated to produce plastic parts. The results indicate that "Cross-functional team work", "Setting organization objectives", "Providing on-job training" and "Availability of information" respectively are the most critical success factors for TPM program. Strengthen these factors before adopting the program leads to sustainable achievements. On average, the overall equipment effectiveness "OEE" improved from $60 \%$ to $73.1 \%$ as reported at the beginning of the second quarter in 2017. In additions, it is concluded that TPM applications not influenced by the type of products or product design considerations.

\section{REFERENCES}

[1] Moubray J., "21st Century Maintenance Organization Part I: The Asset Management Model", Maintenance Technology, Vol. 16, No. 2, pp. 25-32 (2003).

[2] Ahuja, I. P. and Khamba, J. S., "Total Productive Maintenance: Literature Review and Directions", International Journal of Quality \& Reliability Management, Vol. 25, pp. $709-756$ (2008).

[3] Cooke F. L., "Implementing TPM in Plant Maintenance: Some Organizational Barriers", International Journal of Quality \& Reliability Management, Vol. 17, No. 9, pp. $1003-1016$ (2000).

[4] Nakajima S., "TPM Development Program: Implementing Total Productive Maintenance", United States of America (1989).

[5] Dossenbach T., "Implementing Total Productive Maintenance", Wood and Wood Products, Vol. 111, No. 2, pp. 29-32 (2006).

[6] Nakajima S., "Introduction to TPM", (Cambridge: Productivity Press In, 1988).

[7] Ahuja I. P. S., Khamba J. S. and Choudhary R., "Improved Organizational Behavior through Strategic Total Productive Maintenance Implementation", Proc. International Mechanical Engineering Congress and Exposition (IMECE), pp. 1-8, November (2006).

[8] Rodrigues M. and Hatakeyama K., "Analysis of the Fall of TPM in Companies", J. of Mate. Process Techno., pp. 276-279 (2006).

[9] Gregory A., "Number Cruncher - Overall Equipment Effectiveness and Total Productive Maintenance", Vol. 59, No. 7, (Work Manage, 2006), 18-20.

[10] Ahuja I. P. S., and Khamba J. S., "Strategies and Success Factors for Overcoming Challenges In TPM Implementation in Indian Manufacturing Industry", Journal of Quality in Maintenance Engineering, 14(2), 123-147 (2008).

[11] Mad Lazim H., and Ramayah T., "Maintenance Strategy in Malaysian Manufacturing Companies: A Total Productive Maintenance (TPM) Approach", Business Strategy Series, 11(6), 387-396 (2010).

[12] Bamber C. J., Sharp J. M., and Hides M. T., "Factors Affecting Successful Implementation of Total Productive Maintenance: A UK Manufacturing Case Study Perspective", Journal of Quality in Maintenance engineering, 5(3), 162181 (1999). 
[13] Lin X. J., Lin Q., and Zhang G. N., "Affectivity of Total Productive Maintenance (TPM) in Large Size Organizations-A Case Study in Shandong Lingong", InApplied Mechanics and Materials, (Vol. 701, pp. 1249-1252). Trans. Tech. Publications (2015).

[14] Friedli T., Goetzfried M., and Basu P., "Analysis of the Implementation of Total Productive Maintenance, Total Quality Management, and Just in Time in Pharmaceutical Manufacturing", Journal of Pharmaceutical Innovation, 5(4), 181-192 (2010).

[15] Lycke L. and Akersten P.A., "Experiences of Implementing TPM in Swedish Industries", International Journal of Reliability and Application, 1(1), pp. 114 (2000).

[16] Parida and Kumar, "Maintenance Performance Measurement: Issues and Challenges", Journal of Quality in Maintenance Engineering, vol. 12, pp. 23951, (2006).

[17] Rodrigues and K. Hatakeyama, "Analysis of the Fall of TPM in Companies", Journal of Materials Processing Technology, vol. 179, pp. 276-9, 2006.

[18] Hansson J., Backlund F. and Lycke L., "Managing Commitment: Increasing the Odds for Successful Implementation of TQM, TPM Or RCM", International Journal of Quality \& Reliability Management, 20(9), pp. 993-1008 (2003).

[19] Robinson C.J. and Ginder A.P., The North American Experience (Portland: Productivity Press, 1995).

[20] Groote P.D., "Maintenance Performance Analysis: A Practical Approach", Journal of Quality in Maintenance Engineering, 1 (2), pp. 4-24 (1995).

[21] Bohoris G.A., Vamvalis C., Tracey W. and Ignatiadou K., "TPM Implementation in Land -Rover with Assistance of a CMMS", Journal of Quality in Maintenance Engineering, 1(4), pp. 3 -16 (1995).

[22] Hutchins D., "Introducing TPM", Manufacturing Engineer, 77(1), pp. 34-37 (1998).

[23] Blanchard B.S., "An Advance Approach for Implementing TPM in Manufacturing Environment", Journal of Quality in Maintenance Engineering, 5, pp. 162-181 (1997).

[24] Davis R., "Productivity Improvements through TPM", (Englewood Cliffs: Prentice-Hall, 1995).

[25] Fredendall L.D., Patterson J.W., Kennedy W.J. and T. Griffin, "Maintenance Modeling, its Strategic Impact", Journal of Managerial Issues, 9(4), pp. 440-453 (1997).

[26] Ben-Daya M. and Duffuaa S. O., "Maintenance and Quality: The Missing Link", Journal of Quality in Maintenance Engineering, 1, pp. 20-26 (1995).

[27] McKone K.E., Roger G.S. and Cua K.O., "The Impact of Total Productive Maintenance Practices on Manufacturing Performance", Journal of Operations Management, Vol. 19, No. 1, pp. 39-58 (2001).

[28] Alorom M., "The Implementation of Total Productive Maintenance in The Libyan Heavy Industry", Doctoral dissertation, Coventry University, U.K. (2015).

[29] Mohammed L., and Mohanad S., "Developing Total Productive Maintenance Model (TPM) For Small Medium Size Enterprises", (2017).

[30] Falatoonitoosi E., Leman Z., Sorooshian S., and Salimi M., "Decision Making Trial and Evaluation Laboratory", Research Journal of Applied Science, Engineering and technology 5(13): 3476-3480 (2013).

[31] Tamura M., Nagata H. and Akazawa K., "Extraction and System Analysis of Factors that Prevent Safety and Security by Structural Models", 41st SICE Annual Conference, Osaka, Japan (2002). 


\section{List of Tables:}

Table 1. The Direct/Average Matrix.

\begin{tabular}{|c|c|c|c|c|c|c|c|c|c|c|c|c|c|c|c|c|c|c|c|c|c|}
\hline Code & SF1 & SF2 & SF3 & SF4 & SF5 & SF6 & SF7 & SF8 & SF9 & SF10 & SF11 & SF12 & SF13 & SF14 & SF15 & SF16 & SF17 & SF18 & SF19 & SF20 & Total \\
\hline SF1 & 0.00 & 2.90 & 2.00 & 2.00 & 2.00 & 2.90 & 2.00 & 0.90 & 0.90 & 0.90 & 0.90 & 2.00 & 0.90 & 2.00 & 2.00 & 0.00 & 0.90 & 0.00 & 2.90 & 2.90 & 22.30 \\
\hline SF2 & 0.00 & 0.00 & 0.90 & 0.00 & 0.90 & 0.90 & 2.00 & 0.90 & 2.90 & 2.00 & 2.00 & 2.90 & 0.00 & 0.90 & 2.00 & 0.00 & 2.00 & 0.90 & 0.00 & 0.00 & 16.30 \\
\hline SF3 & 0.00 & 0.00 & 0.00 & 2.00 & 2.90 & 0.90 & 2.00 & 0.90 & 0.00 & 0.90 & 0.90 & 2.00 & 0.90 & 0.00 & 2.90 & 0.90 & 2.90 & 2.90 & 2.00 & 0.00 & 13.40 \\
\hline SF4 & 2.90 & 0.90 & 0.90 & 0.00 & 2.00 & 2.90 & 2.90 & 2.90 & 2.90 & 2.00 & 0.90 & 2.00 & 2.00 & 0.90 & 2.00 & 0.00 & 2.00 & 0.90 & 0.90 & 0.90 & 26.10 \\
\hline SF5 & 0.90 & 2.90 & 2.00 & 2.90 & 0.00 & 2.90 & 2.90 & 2.90 & 2.00 & 2.00 & 2.00 & 2.90 & 2.00 & 2.90 & 2.90 & 0.90 & 2.90 & 2.00 & 2.90 & 0.90 & 31.20 \\
\hline SF6 & 2.90 & 2.90 & 2.90 & 2.90 & 2.90 & 0.00 & 2.90 & 2.90 & 2.90 & 2.00 & 0.90 & 2.90 & 0.90 & 2.90 & 2.00 & 0.90 & 2.00 & 0.90 & 0.90 & 2.00 & 32.80 \\
\hline SF7 & 2.90 & 2.90 & 0.90 & 2.00 & 2.90 & 0.90 & 0.00 & 2.90 & 0.90 & 0.90 & 0.90 & 2.90 & 0.90 & 2.00 & 0.90 & 0.00 & 2.00 & 0.90 & 2.90 & 2.00 & 23.90 \\
\hline SF8 & 0.00 & 2.90 & 0.90 & 0.90 & 2.90 & 2.90 & 2.90 & 0.00 & 0.00 & 2.90 & 2.00 & 2.90 & 0.00 & 0.90 & 0.90 & 0.90 & 2.00 & 0.90 & 2.00 & 2.00 & 22.10 \\
\hline SF9 & 2.00 & 0.90 & 2.00 & 2.00 & 2.90 & 2.90 & 0.90 & 2.00 & 0.00 & 2.00 & 0.90 & 2.00 & 0.90 & 0.00 & 2.90 & 0.90 & 2.90 & 2.00 & 0.00 & 2.90 & 21.40 \\
\hline SF10 & 0.90 & 1.50 & 1.00 & 1.50 & 1.90 & 2.40 & 2.40 & 1.40 & 0.50 & 0.00 & 2.90 & 2.90 & 0.50 & 1.40 & 2.40 & 0.90 & 2.40 & 1.40 & 1.00 & 0.50 & 21.20 \\
\hline SF11 & 2.00 & 2.90 & 2.00 & 2.90 & 2.90 & 0.00 & 2.90 & 2.90 & 0.90 & 2.00 & 0.00 & 2.90 & 0.90 & 0.90 & 2.90 & 0.90 & 2.90 & 2.90 & 2.00 & 0.90 & 26.10 \\
\hline SF12 & 1.00 & 1.10 & 1.00 & 2.00 & 1.10 & 1.10 & 1.10 & 1.10 & 1.00 & 2.00 & 2.00 & 0.00 & 1.00 & 1.10 & 1.10 & 1.00 & 1.10 & 1.10 & 1.10 & 1.00 & 16.60 \\
\hline SF13 & 2.90 & 0.90 & 0.90 & 0.90 & 2.00 & 2.90 & 0.90 & 0.90 & 0.00 & 2.00 & 2.00 & 0.90 & 0.00 & 0.90 & 0.90 & 0.90 & 0.90 & 0.00 & 0.00 & 0.90 & 18.10 \\
\hline SF14 & 0.00 & 2.00 & 0.90 & 0.00 & 0.00 & 0.00 & 0.00 & 0.00 & 0.90 & 0.90 & 0.90 & 0.00 & 0.00 & 0.00 & 0.90 & 2.00 & 2.00 & 0.90 & 0.00 & 0.00 & 5.60 \\
\hline SF15 & 0.00 & 2.90 & 0.90 & 0.90 & 2.90 & 2.00 & 2.90 & 2.90 & 0.90 & 0.90 & 2.00 & 2.90 & 0.00 & 0.00 & 0.00 & 0.00 & 2.00 & 2.00 & 2.00 & 2.90 & 22.10 \\
\hline SF16 & 0.00 & 0.00 & 0.90 & 0.00 & 0.00 & 2.00 & 0.00 & 0.00 & 0.00 & 0.00 & 0.90 & 0.00 & 0.90 & 2.00 & 0.00 & 0.00 & 0.00 & 0.00 & 0.00 & 0.00 & 6.70 \\
\hline SF17 & 0.90 & 2.00 & 0.90 & 2.00 & 0.90 & 0.90 & 0.90 & 0.90 & 0.90 & 0.90 & 0.90 & 0.00 & 0.00 & 2.90 & 0.90 & 0.00 & 0.00 & 2.90 & 2.00 & 0.90 & 15.00 \\
\hline SF18 & 0.00 & 2.00 & 2.00 & 0.90 & 2.00 & 0.90 & 0.00 & 2.00 & 0.90 & 0.90 & 2.90 & 0.90 & 2.00 & 2.00 & 2.90 & 0.90 & 2.00 & 0.00 & 2.00 & 0.00 & 19.40 \\
\hline SF19 & 0.90 & 0.90 & 0.90 & 2.00 & 2.90 & 2.90 & 2.00 & 2.90 & 2.90 & 0.90 & 2.00 & 0.90 & 2.90 & 0.90 & 2.00 & 0.90 & 0.90 & 2.00 & 0.00 & 2.00 & 25.90 \\
\hline SF20 & 0.90 & 2.90 & 0.90 & 0.90 & 2.90 & 0.90 & 2.00 & 2.00 & 0.00 & 0.90 & 0.00 & 2.90 & 0.00 & 0.00 & 2.90 & 0.00 & 0.90 & 0.90 & 0.90 & 0.00 & 17.20 \\
\hline
\end{tabular}

Table 2. The Normalized Matrix.

\begin{tabular}{|c|c|c|c|c|c|c|c|c|c|c|c|c|c|c|c|c|c|c|c|c|}
\hline ode & SF1 & SF2 & SF3 & SF4 & SF5 & SF6 & SF7 & SF8 & SF9 & SF10 & SF11 & SF12 & SF13 & SF14 & SF15 & SF16 & SF17 & SF18 & SF19 & SF20 \\
\hline SF1 & 0.00 & 0.09 & 0.06 & 0.06 & 0.06 & 0.09 & 0.06 & 0.03 & 0.03 & 0.03 & 0.03 & 0.06 & 0.03 & 0.06 & 0.06 & 0.00 & 0.03 & 0.00 & 0.09 & 0.09 \\
\hline SF2 & 0.00 & 0.00 & 0.03 & 0.00 & 0.03 & 0.03 & 0.06 & 0.03 & 0.09 & 0.06 & 0.06 & 0.09 & 0.00 & 0.03 & 0.06 & 0.00 & 0.06 & 0.03 & 0.00 & 0.00 \\
\hline SF3 & 0.00 & 0.00 & 0.00 & 0.06 & 0.09 & 0.03 & 0.06 & 0.03 & 0.00 & 0.03 & 0.03 & 0.06 & 0.03 & 0.00 & 0.09 & 0.03 & 0.09 & 0.09 & 0.06 & 0.00 \\
\hline SF4 & 0.09 & 0.03 & 0.03 & 0.00 & 0.06 & 0.09 & .09 & 0.09 & 0.09 & 0.06 & 0.03 & 0.06 & 0.06 & 0.03 & 0.06 & 0.00 & 0.06 & 0.03 & 0.03 & 0.03 \\
\hline SF5 & 0.03 & 0.09 & 0.06 & 0.09 & 0.00 & 0.09 & 0.09 & 0.09 & 0.06 & 0.06 & 0.06 & 0.09 & 0.06 & 0.09 & 0.09 & 0.03 & 0.09 & 0.06 & 0.09 & 0.03 \\
\hline SF6 & 0.09 & 0.09 & 0.09 & 0.09 & 0.09 & 0.00 & 0.09 & 0.09 & 0.09 & 0.06 & 0.03 & 0.09 & 0.03 & 0.09 & 0.06 & 0.03 & 0.06 & 0.03 & 0.03 & 0.06 \\
\hline SF7 & 0.09 & 0.09 & 0.03 & 0.06 & 0.09 & 0.03 & 0.00 & 0.09 & 0.03 & 0.03 & 0.03 & 0.09 & 0.03 & 0.06 & 0.03 & 0.00 & 0.06 & 0.03 & 0.09 & 0.06 \\
\hline SF8 & 0.00 & 0.09 & 0.03 & 0.03 & 0.09 & 0.09 & 0.09 & 0.00 & 0.00 & 0.09 & 0.06 & 0.09 & 0.00 & 0.03 & 0.03 & 0.03 & 0.06 & 0.03 & 0.06 & 0.06 \\
\hline SF9 & 0.06 & 0.03 & 0.06 & 0.06 & 0.09 & 0.09 & 0.03 & 0.06 & 0.00 & 0.06 & 0.03 & 0.06 & 0.03 & 0.00 & 0.09 & 0.03 & 0.09 & 0.06 & 0.00 & 0.09 \\
\hline SF10 & 0.03 & 0.05 & 0.03 & 0.05 & 0.06 & 0.07 & 0.07 & 0.04 & 0.02 & 0.00 & 0.09 & 0.09 & 0.02 & 0.04 & 0.07 & 0.03 & 0.07 & 0.04 & 0.03 & 0.02 \\
\hline F11 & 0.06 & 0.09 & 0.06 & 0.09 & 0.09 & 0.00 & 0.09 & 0.09 & 0.03 & 0.06 & 0.00 & 0.09 & 0.03 & 0.03 & 0.09 & 0.03 & 0.09 & 0.09 & 0.06 & 0.03 \\
\hline SF12 & 0.03 & 0.03 & 0.03 & 0.06 & 0.03 & 0.03 & 0.03 & 0.03 & 0.03 & 0.06 & 0.06 & 0.00 & 0.03 & 0.03 & 0.03 & 0.03 & 0.03 & 0.03 & 0.03 & 0.03 \\
\hline FF13 & 0.09 & 0.03 & 0.03 & 0.03 & 0.06 & 0.09 & 0.03 & 0.03 & 0.00 & 0.06 & 0.06 & 0.03 & 0.00 & 0.03 & 0.03 & 0.03 & 0.03 & 0.00 & 0.00 & 0.03 \\
\hline F14 & 0.00 & 0.06 & 0.03 & 0.00 & 0.00 & 0.00 & 0.00 & 0.00 & 0.03 & 0.03 & 0.03 & 0.00 & 0.00 & 0.00 & 0.03 & 0.06 & 0.06 & 0.03 & 0.00 & 0.00 \\
\hline SF15 & 0.00 & 0.09 & 0.03 & 0.03 & 0.09 & 0.06 & 0.09 & 0.09 & 0.03 & 0.03 & 0.06 & 0.09 & 0.00 & 0.00 & 0.00 & 0.00 & 0.06 & 0.06 & 0.06 & 0.09 \\
\hline F16 & 0.00 & 0.00 & 0.03 & 0.00 & 0.00 & 0.06 & 0.00 & 0.00 & 0.00 & 0.00 & 0.03 & 0.00 & 0.03 & 0.06 & 0.00 & 0.00 & 0.00 & 0.00 & 0.00 & 0.00 \\
\hline SF17 & 0.03 & 0.06 & 0.03 & 0.06 & 0.03 & 0.03 & 0.03 & 0.03 & 0.03 & 0.03 & 0.03 & 0.00 & 0.00 & 0.09 & 0.03 & 0.00 & 0.00 & 0.09 & 0.06 & 0.03 \\
\hline F18 & 0.00 & 0.06 & 0.06 & 0.03 & 0.06 & 0.03 & 0.00 & 0.06 & 0.03 & 0.03 & 0.09 & 0.03 & 0.06 & 0.06 & 0.09 & 0.03 & 0.06 & 0.00 & 0.06 & 0.00 \\
\hline F19 & 0.03 & 0.03 & 0.03 & 0.06 & 0.09 & 0.09 & 0.06 & 0.09 & 0.09 & 0.03 & 0.06 & 0.03 & 0.09 & 0.03 & 0.06 & 0.03 & 0.03 & 0.06 & 0.00 & 0.06 \\
\hline F2O & 0.03 & 0.09 & 0.03 & 0.03 & 0.09 & 0.03 & 0.06 & 0.06 & 0.00 & 0.03 & 0.00 & 0.09 & 0.00 & 0.00 & 0.09 & 0.00 & 0.03 & 0.03 & 0.03 & 0.00 \\
\hline
\end{tabular}


Table 3. The Total Relation Matrix.

\begin{tabular}{|c|c|c|c|c|c|c|c|c|c|c|c|c|c|c|c|c|c|c|c|c|c|}
\hline & $\mathrm{F} 1$ & $=2$ & $=3$ & & & & & & F9 & 10 & 11 & 12 & 13 & 14 & F15 & F16 & SF17 & F18 & F19 & & \\
\hline SF1 & & & & & & & & & & & & & & & & & & & & & \\
\hline SF2 & & & & & & & & & & & & & & & & & & & & & \\
\hline SF3 & & & & & & & & & & & & & & & & & & & & & \\
\hline SF4 & & & & & & & & & & & & & & & & & & & & & \\
\hline SF5 & & & & & & & & & & & & & & & & & & & & & \\
\hline SF6 & & & & & & & & & & & & & & & & & & & & & \\
\hline SF7 & & & & & & & & & & & & & & & & & & & & & \\
\hline SF8 & & & & & & & & & & .4 & & & & & & & & & & & \\
\hline SF9 & 0.34 & & & & 61 & 52 & & 53 & 32 & 44 & 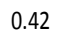 & 0.58 & & & 0.57 & 0.18 & .57 & 43 & 38 & 40 & 82 \\
\hline SF10 & 0.29 & & & & 0.53 & 45 & & & 30 & 120 & 012 & 0.55 & & & 0.50 & & & & & 30 & 89 \\
\hline SF11 & 0.38 & & & & & & & & & & & & & & & & & & & & \\
\hline SF12 & 0.23 & & & & & & & & & & & & & & & & & & & & \\
\hline SF13 & & & & & & & & & & & & & & & & & & & & & \\
\hline SF14 & & & & & & & & & & & & & & & & & & & & & \\
\hline SF15 & 0. & & & & & & & & & & & & & & & & & & & & \\
\hline & & & & & & & & & & & & & & & & & & & & & \\
\hline & & & & & & & & & & & & & & & & & & & & & \\
\hline & & & & & & & & & & & & & & & & & & & & & \\
\hline SF19 & 0.3 & & & & & & & & & & & & & & & & & & & & \\
\hline $\mathrm{SF} 20$ & 0.23 & & & & 0.46 & & & 1.4 & & ) . & ). & 0. & & & 0.42 & & 0.37 & 0.29 & 0.30 & & .24 \\
\hline & & & & & & & & & & & & & & & & & & & & & \\
\hline
\end{tabular}

Table 4. The Results of DEMATEL.

\begin{tabular}{|c|c|c|c|c|c|}
\hline Improvement initiatives & Code & $\begin{array}{c}\text { Impact } \\
\text { given }\left(R_{i}\right)\end{array}$ & $\begin{array}{l}\text { Impact } \\
\text { received } \\
\left(C_{j}\right)\end{array}$ & $\begin{array}{c}\text { Degree of } \\
\text { importance } \\
\left(R_{i}+C_{j}\right)\end{array}$ & $\begin{array}{l}\text { Net effect } \\
\text { (Ri-Cj) }\end{array}$ \\
\hline Cross functional team work & SF5 & 11.11 & 9.92 & 21.03 & 1.19 \\
\hline Setting organization objectives & SF6 & 10.52 & 8.24 & 18.76 & 2.28 \\
\hline Providing on-job training & SF11 & 9.97 & 7.34 & 17.31 & 2.62 \\
\hline Information availability & SF19 & 9.18 & 6.99 & 16.17 & 2.19 \\
\hline $\begin{array}{l}\text { Alignment TPM objectives with } \\
\text { organization objectives }\end{array}$ & SF4 & 8.96 & 7.64 & 16.60 & 1.32 \\
\hline $\begin{array}{l}\text { Monitoring and controlling of } \\
\text { maintenances KPls }\end{array}$ & SF9 & 8.82 & 5.99 & 14.81 & 2.83 \\
\hline Culture change & SF7 & 8.49 & 9.02 & 17.50 & -0.53 \\
\hline $\begin{array}{l}\text { Supporting small group activity } \\
\text { toward implementing autonomous } \\
\text { maintenance }\end{array}$ & SF15 & 8.46 & 9.03 & 17.49 & -0.58 \\
\hline $\begin{array}{l}\text { Top management involvement and } \\
\text { commitment }\end{array}$ & SF1 & 8.21 & 5.41 & 13.62 & 2.80 \\
\hline $\begin{array}{l}\text { Utilizing the continuous } \\
\text { improvement approach }\end{array}$ & SF8 & 8.19 & 8.90 & 17.09 & -0.70 \\
\hline $\begin{array}{l}\text { Applying reliability improvement } \\
\text { pilot projects }\end{array}$ & SF10 & 7.89 & 7.22 & 15.11 & 0.66 \\
\hline Maintenance work documenting & SF18 & 7.01 & 6.91 & 13.93 & 0.10 \\
\hline Resources planning & SF3 & 6.81 & 6.37 & 13.18 & 0.44 \\
\hline $\begin{array}{l}\text { Establishment of a rewarding } \\
\text { system }\end{array}$ & SF20 & 6.24 & 5.98 & 12.22 & 0.26 \\
\hline Employee involvement & SF12 & 6.06 & 9.81 & 15.87 & -3.75 \\
\hline $\begin{array}{l}\text { Conducting } \quad \text { benchmarking } \\
\text { activities }\end{array}$ & SF13 & 5.96 & 4.27 & 10.24 & 1.69 \\
\hline Applying $5 S$ program & SF2 & 5.69 & 9.44 & 15.13 & -3.76 \\
\hline $\begin{array}{ll}\text { Executing } & \text { planned/preventive } \\
\text { maintenance }\end{array}$ & SF17 & 5.55 & 9.16 & 14.71 & -3.61 \\
\hline $\begin{array}{ll}\text { Early equipment } & \text { design } \\
\text { consideration }\end{array}$ & SF14 & 2.48 & 6.51 & 8.99 & -4.04 \\
\hline Early product design consideration & SF16 & 1.62 & 3.04 & 4.66 & -1.42 \\
\hline
\end{tabular}


Table 5. Monthly value of OEE and its components.

\begin{tabular}{|c|c|c|c|c|}
\hline$\frac{\Phi}{\stackrel{0}{D}}$ & 岂 & 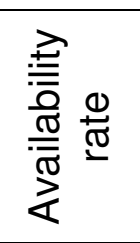 & 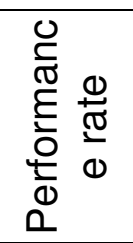 & 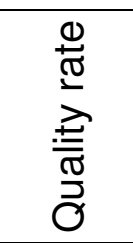 \\
\hline Jan-16 & $59.9 \%$ & $70.0 \%$ & $90.0 \%$ & $95.0 \%$ \\
\hline Feb-16 & $59.6 \%$ & $69.0 \%$ & $90.0 \%$ & $96.0 \%$ \\
\hline Mar-16 & $61.0 \%$ & $71.0 \%$ & $90.5 \%$ & $95.0 \%$ \\
\hline Apr-16 & $61.6 \%$ & $72.0 \%$ & $91.0 \%$ & $94.0 \%$ \\
\hline May-16 & $64.0 \%$ & $74.0 \%$ & $91.0 \%$ & $95.0 \%$ \\
\hline Jun-16 & $63.0 \%$ & $76.0 \%$ & $91.0 \%$ & $95.0 \%$ \\
\hline Jul-16 & $65.9 \%$ & $75.0 \%$ & $92.0 \%$ & $95.5 \%$ \\
\hline Aug-16 & $64.7 \%$ & $74.0 \%$ & $92.0 \%$ & $95.0 \%$ \\
\hline Sep-16 & $66.8 \%$ & $76.0 \%$ & $92.0 \%$ & $95.5 \%$ \\
\hline Oct-16 & $67.1 \%$ & $76.0 \%$ & $92.0 \%$ & $96.0 \%$ \\
\hline Nov-16 & $68.4 \%$ & $77.0 \%$ & $92.5 \%$ & $96.0 \%$ \\
\hline Dec-16 & $72.3 \%$ & $81.0 \%$ & $92.5 \%$ & $96.5 \%$ \\
\hline Jan-17 & $73.6 \%$ & $82.0 \%$ & $92.5 \%$ & $97.0 \%$ \\
\hline Feb-17 & $73.4 \%$ & $81.0 \%$ & $93.0 \%$ & $97.5 \%$ \\
\hline Mar-17 & $72.2 \%$ & $80.0 \%$ & $93.0 \%$ & $97.0 \%$ \\
\hline
\end{tabular}

\section{List of Figures:}

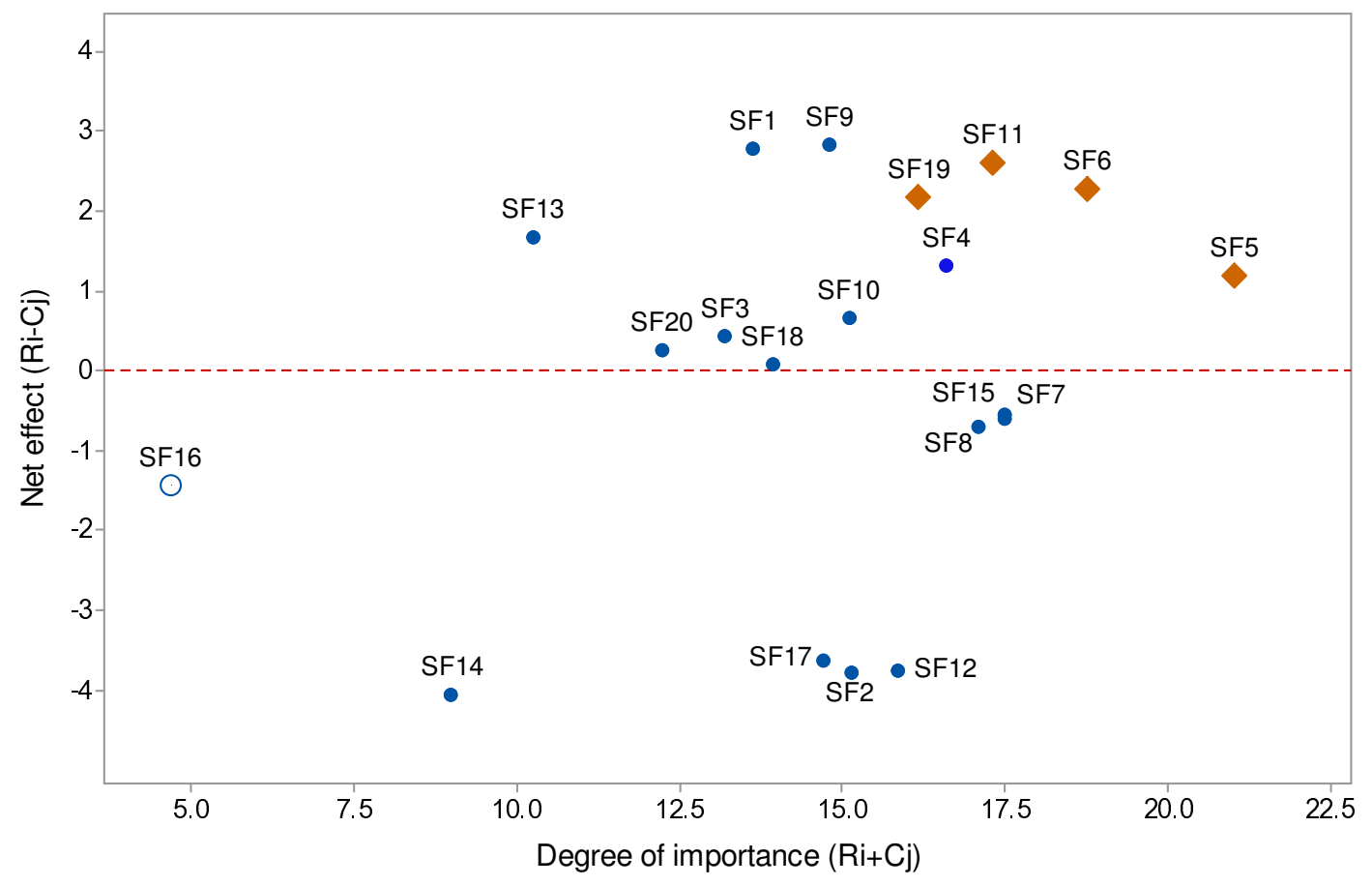

Fig. 1. Causal diagram of the success factors 


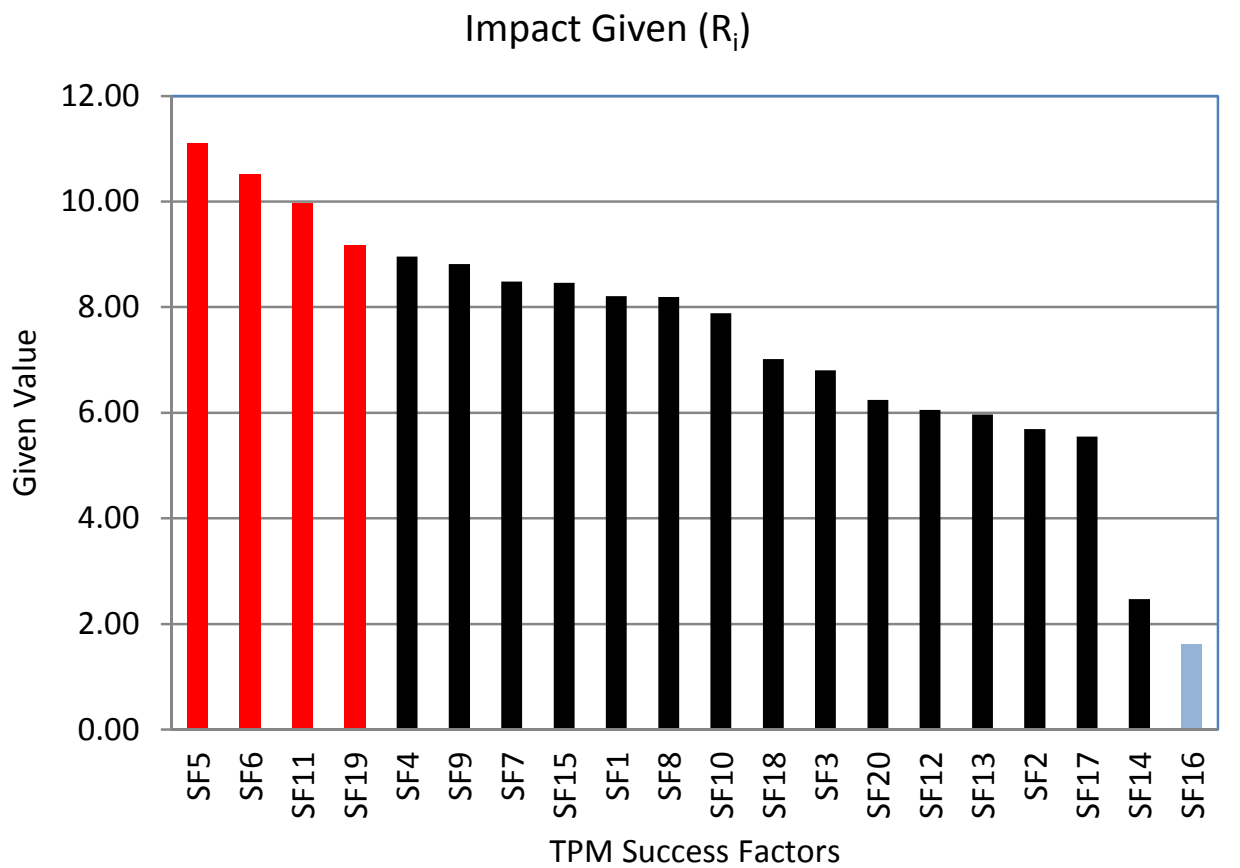

Fig. 2. Ranking of TPM success factors based on given value (Ri)

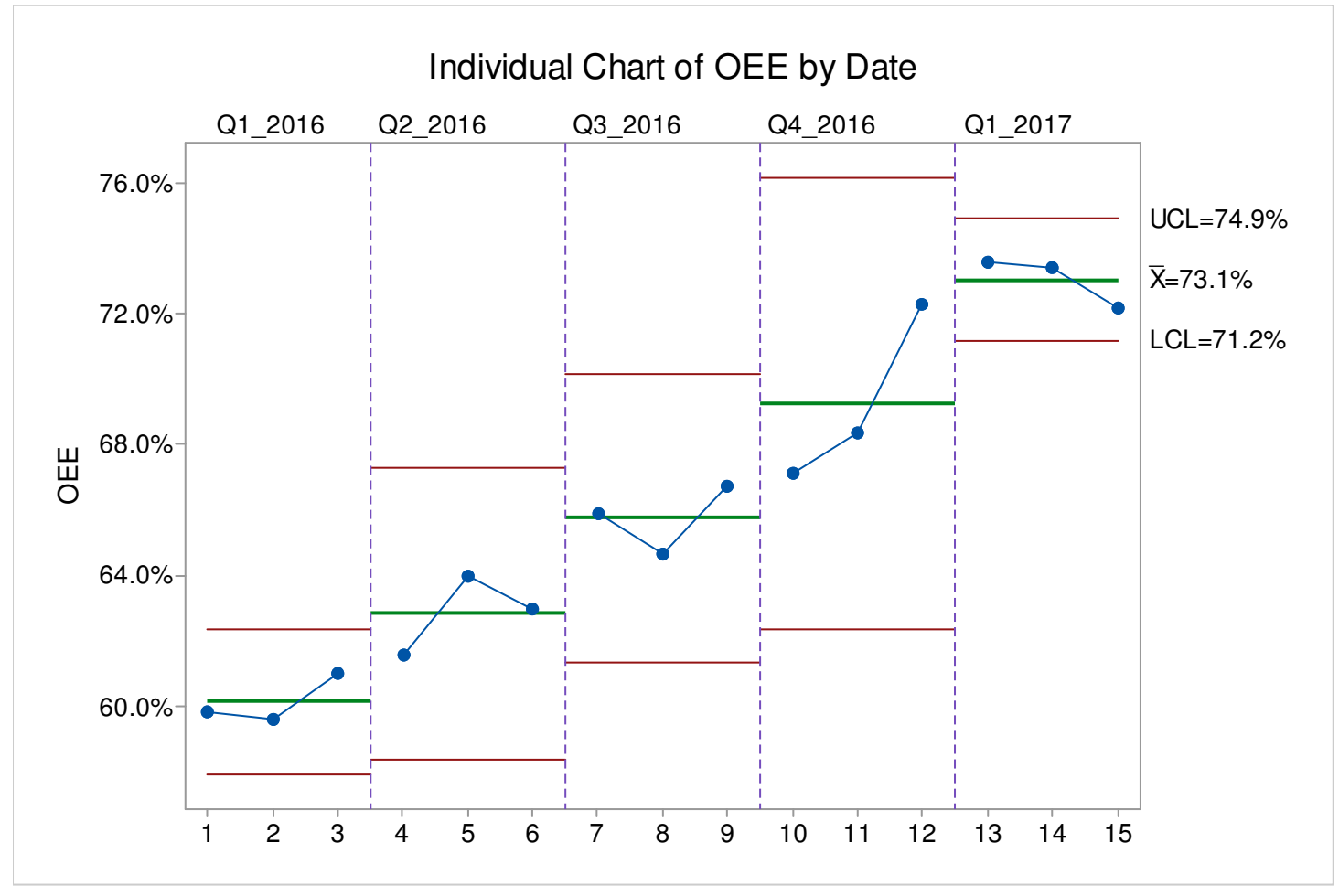

Fig. 3. OEE improvement in 2016 